\title{
A EDUCAÇÃO BRASILEIRA À LUZ DA CONCEPÇÃO PEDAGÓGICA DE ANTON MAKARENKO
}

\author{
LA EDUCACIÓN BRASILEÑA A LA LUZ DE LA CONCEPCIÓN PEDAGÓGICA DE \\ ANTON MAKARENKO
}

\section{BRAZILIAN EDUCATION IN THE LIGHT OF ANTON MAKARENKO'S PEDAGOGICAL CONCEPTION}

DOI: http://dx.doi.org/10.9771/gmed.v12i3.37508

\author{
Samara Sales Frazão ${ }^{1}$ \\ Maria Cleide da Silva Barroso ${ }^{2}$
}

\begin{abstract}
Resumo: O presente artigo trata de pesquisa bibliográfica que tem como objetivo refletir sobre a contribuição da concepção pedagógica do pedagogo russo Anton Semionóvitch Makarenko (1888-1939) à educação brasileira na contemporaneidade. A fim de contribuição com nossas reflexões, elencamos autores como Oliveira (2012), Cury e Mouta (2014) e Baía e Machado (2020) que sinalizam as características da pedagogia makarenkiana, na qual tem como principal preceito a coletividade, desenvolvido a partir da experiência educacional da Colônia de Gorki, situada na então União das Repúblicas Socialistas Soviéticas (URSS). Encontramos na concepção pedagógica de Makarenko consonância com os tempos atuais, nos quais a educação, no e para o coletivo, ainda faz-se um desafio para os sistemas educacionais e para a sociedade.
\end{abstract}

Palavras-chave: pedagogia russa; Anton Makarenko; coletividade.

Resumen: El presente artículo trata de pesquisa bibliográfica que tiene como objetivo reflejar sobre la contribución de la concepción pedagógica del pedagogo ruso Anton Semionóvitch Makarenko (1888-1939) a la educación brasileña en la contemporaneidade. A fin de contribución con nuestras reflexiones, elencamos autores como Oliveira (2012), Cury y Mouta (2014) y Bahía y Machado (2020) que señalizan las características de la pedagogía makarenkiana, en la cual tiene como principal precepto la coletividade, desenvuelto a partir de la experiencia educacional de la Colonia de Gorki, situada en la entonces Unión de las Repúblicas Socialistas Soviéticas (URSS). Encontramos en la concepción pedagógica de Makarenko consonância con los tiempos actuales, en los cuales la educación en el y para el colectivo aún se hace un desafío para los sistemas educacionales y para la sociedad.

Palabras clave: pedagogía rusa; Anton Makarenko; coletividade.

Abstract: This article deals with bibliographic research that aims to reflect on the contribution of the pedagogical conception of the Russian pedagogue Anton Semionóvitch Makarenko (1888-1939) to Brazilian education in contemporary times. In order to contribute to our reflections, we list authors such as Oliveira (2012), Cury and Mouta (2014) and Baía and Machado (2020) who signal the characteristics of the Makariank pedagogy, in which the main precept is the collectivity, developed from experience educational institution of the Gorki Colony, located in the then Union of Soviet Socialist Republics (USSR). We find in the pedagogical conception of Makarenko consonance with the current times, in which education in and for the collective is still a challenge for educational systems and for society.

Keywords: Russian pedagogy; Anton Makarenko; collectivity.

\section{Introdução}


Não é de hoje que os professores brasileiros têm que lidar com vários desafios no contexto escolar, mas as dificuldades têm aumentado nos últimos anos no mesmo ritmo em que aumentam as desigualdades sociais e a criminalidade. Em sala de aula, esses profissionais precisam, muitas vezes, exercer funções que vão para além do ensino de conhecimentos e habilidades; funções que não são aprendidas nos cursos de magistério, mas necessárias àqueles que almejam contribuir significativamente para a formação integral de seus alunos.

Nesse sentido, lança-se luz nesse artigo à concepção pedagógica de Anton Makarenko, que mesmo em meio à caótica situação da sociedade soviética após a Primeira Guerra Mundial e a Revolução Russa, superou diversos desafios enquanto professor e diretor de menores infratores e abandonados, exercendo não só a função pedagógica de ensinar disciplinas, mas também a função política de readaptálos para a vida em sociedade.

Anton Makarenko, influenciado pelas leituras de Marx, Lenin, Gorki, Engels e Krupskaia, buscou dar respostas através de um método baseado na coletividade, dotando seus educandos com o senso de responsabilidade e de pertença a um grupo, e fornecendo-lhes meios de agir sobre a realidade. Foi duramente criticado por sua rigidez pedagógica por muitos especialistas da educação de sua época, mas teve sua pedagogia reconhecida, sendo condecorado antes de falecer com a Ordem da Bandeira Vermelha do Trabalho, que era uma homenagem dada somente às pessoas que prestaram grandes serviços ao Estado Soviético.

Assim, este artigo tem como objetivo refletir sobre a contribuição da concepção pedagógica de Makarenko à educação brasileira na contemporaneidade, apresentando inicialmente uma breve análise biográfica, seguida de comentários sobre a sua teoria e reflexões relacionando suas contribuições à realidade da educação brasileira.

\section{Breve análise biográfica de Anton Makarenko}

Anton Semyonovich Makarenko (1888-1939) nasceu na cidade ucraniana Belopolye, em uma família pobre, sendo seu pai operário ferroviário e sua mãe uma dona de casa. Assim como a maioria das crianças pobres na sociedade russa, que vivia sob o regime czarista, aprendeu a ler e a escrever com sua mãe, de modo que, ao ser matriculado na escola primária já sabia ler. Nesta escola ele não podia usar sua língua materna, pois esta havia sido proibida pelo império czarista. Além disso, não teve acesso a disciplinas exclusivas da elite, como a Lógica e a Filosofia, no entanto, tornou-se mestre em ambas na sua prática pedagógica.

Ao tratar da biografia do pedagogo ucraniano, Oliveira (2012) informa que aos dezesseis anos, ele procurou emprego como professor na fábrica onde seu pai trabalhava. Aos dezessete, concluiu o magistério, em 1917, e vai ensinar na escola das oficinas ferroviárias, onde trabalha por oito anos. Essa sua inserção como professor em ambiente de trabalho vai influenciar a pedagogia construída por ele ao longo de sua prática pedagógica, onde relaciona escola e trabalho. 
Em seguida, torna-se diretor de uma escola secundária, onde vai modificar o currículo escolar incluindo o ensino de língua ucraniana, baseado em ideias socialistas após o contato com as ideias de Lenin e Marx Mongorg. Após isso, Makarenko iniciará a mais significativa experiência de sua biografia: a atuação como diretor em uma colônia destinada à formação educacional e à recuperação social de menores abandonados e infratores, posteriormente denominada por seus membros de Colônia Gorki.

Ferreira, Marafon e Santos (2009) explicam que Anton Makarenko foi profundamente influenciado pelo escritor e humanista russo Máximo Gorki, com o qual mantinha contato e trocava correspondências. Vale ressaltar que Gorki também teve uma infância pobre e morou nas ruas, como muitos daqueles que estavam na Colônia em Poltava, mas encontrou nos livros o meio de libertar-se das injustiças sociais. Por isso, Makarenko estimulava a leitura de seus livros, principalmente da trilogia autobiográfica "Infância", "Ganhando meu Pão" e "Minhas Universidades". Desse modo, o autor passa a ser modelo de superação para aqueles jovens da colônia.

A Colônia Gorki teve três sedes, em Poltava, Trepke e Kuriaj, tendo Makarenko como diretor, e cada sede correspondia aos estágios de aprofundamento e desenvolvimento de sua pedagogia. Essa experiência foi publicada por ele no livro "Poema Pedagógico", onde escreveu sua teoria pedagógica em forma de novela, descrevendo a sua prática com os educandos e, ao mesmo tempo, revolucionando a educação de sua época. Bretas e Novaes (2016, p. 404) entendem "que se trata de sua principal obra educacional, possuidora de inegável valor literário, uma vez que abre mão da escrita do gênero textual científico, para narrar a construção de um difícil processo educativo na Colônia Gorki (1920 a 1928)." Provavelmente, Makarenko não tinha a consciência de que ao descrever sua experiência estava escrevendo uma das mais importantes teorias pedagógicas do século XX.

$\mathrm{Na}$ primeira sede, em Poltava, os educandos aprenderam a trabalhar em coletivo na gestão da colônia. Na segunda sede, em Trepke, Makarenko começa a colher os primeiros frutos de sua pedagogia, pois nesse período a primeira geração de gorkianos, como eram chamados os internos da Colônia Gorki, entrou na faculdade operária, a Rabfak. Esses jovens não deixaram de manter contato e escreviam frequentemente para animar os colegas da colônia e os novos ingressantes. Ademais, eles tinham a comprovação daquilo que o mestre sempre lhes dizia: Nunca mais ladrões, nem mendigos! Somos os dirigentes. Esse era o lema de Makarenko (FILONOV, 2010).

A última sede representou um novo começo para Makarenko, pois foi convidado pelo governo educacional a assumir uma instituição de ressocialização de menores infratores e abandonados que funcionava, mas estava praticamente abandonada. Mas foi diante dos inúmeros desafios, ao iniciar o trabalho com mais de quinhentos educandos, que ele consolidou a sua pedagogia, pois agora tinha uma visão clara do trabalho pedagógico que deveria realizar com aqueles educandos (FILONOV, 2010).

Embora Makarenko tenha alcançado êxito na Colônia Gorki, foi duramente criticado por sua rigidez como diretor, sendo a organização da colônia comparada a um centro de treinamento militar. Makarenko aplicava castigos aos colonistas que não cumpriam com as suas obrigações prejudicando assim o coletivo. Essas punições eram, em geral, a eliminação do grupo, ou como acontecidos, algumas vezes, castigos físicos. Destaca-se um trecho em que o próprio pedagogo afirma sua atitude 
Sim, eu surrei um educando. Vivenciei todo o absurdo pedagógico, toda a ilegalidade jurídica daquele incidente, mas ao mesmo tempo vi que a limpeza das minhas mãos pedagógicas era assunto de importância secundária em confronto com o problema que eu tinha pela frente. (MAKARENKO, 1985, p. 29 apud BRETAS; NOVAES, 2016, p. 412).

Visto que o pedagogo compreendia que diante da realidade que se apresentava a teoria por si só não atendia suas expectativas e por essa via, ele comungava com um modelo de cidadão perfeito defendido pelo regime soviético.

Feigel (2015), em sua análise sobre Poema Pedagógico expõe que, após muito se desgastar com a burocracia do Estado e com as críticas de especialistas em educação, Makarenko passou a repensar a ideia de dirigir apenas colônias e passou a se interessar por novos projetos educacionais que proporcionassem a criação de novas experiências educacionais de coletivos autogeridos. Neste sentido, em 1928 pede demissão da Colônia Gorki, após ser acusado de adotar um sistema de educação não soviético em sua instituição. Mas continuou como diretor na Comuna Dzerjinski, que permitia a ele mais autonomia no seu trabalho pedagógico. Sua experiência nesta última instituição foi descrita no livro Bandeiras Sobre as Torres (FEIGEL, 2015).

Anton Makarenko publicou peças de teatro e novelas, sempre com teor educativo. Dentre as suas principais obras estão: Poema Pedagógico, Bandeiras Sobre as Torres e Livro dos Pais; sendo este último escrito em parceria com a esposa. O pedagogo ucraniano valorizava muito a instituição familiar na educação do homem para a nova sociedade; o tipo de cidadão do qual a sociedade soviética precisava para se reestruturar naquele momento pós-guerras e revoluções.

Quiçá por presenciar em seus educandos as consequências da ausência familiar, Makarenko percebeu o fulcral papel desta instituição na formação do indivíduo. A família estava em crise na União Soviética, como reflexo do contexto político e cultural nas primeiras décadas do século XX. Diante disso, Makarenko cria na Colônia Gorki um ambiente onde os educandos se sentissem em casa, em família, e ao mesmo tempo, no mundo do trabalho, dando responsabilidades práticas a cada educando. Sua intenção era a formação de um novo homem, "que seja trabalhador e culto, que saiba comandar e subordinar-se em uma sociedade que tem como finalidade abolir as diferenças de classes" (CURY; MOUTA, 2014, p. 18, tradução nossa) $)^{3}$.

Embora muito perseguido pela sua pedagogia, sendo criticado por especialistas da educação pelos métodos rígidos e parecidos com técnicas militares, antes de sua morte teve a sua pedagogia reconhecida em seu país como o melhor meio de formação do novo homem soviético, sendo condecorado com a Ordem da Bandeira Vermelha do Trabalho.

Em 1939, morre em uma viagem de trem de um ataque cardíaco, aos 51 anos, após dedicar toda a sua vida à educação e construir um modelo de pedagogia universal, que tem por base o trabalho coletivo.

\section{O Modelo de educação de Anton Makarenko}

Baía e Machado (2019), ao escreverem sobre a pedagogia de Anton Makarenko, explicam que o contexto no qual o pedagogo estava inserido era desafiador, pois a Rússia sofria as consequências danosas 
do império czar e pós Primeira Guerra Mundial. Por ser de família pobre, Makarenko sentiu na pele as consequências da desigualdade social e a miséria em que vivia a classe trabalhadora. Segundo as autoras, a Rússia estava fragilizada política e economicamente, tendo atingido o auge de 7,5 milhões de menores abandonados e em moradias precárias.

Segundo Aranha (2006), estima-se que a população soviética era em sua maioria analfabeta, cerca de 90\%; uma das consequências da Primeira Guerra, da Guerra Civil e da Revolução Russa, que deixaram marcas na educação de todos os países do leste europeu. Desse modo, o modelo de educação que urgia naquele momento era um que não somente alfabetizasse, mas que se preocupasse com a formação integral do indivíduo, principalmente para atuar na transformação da sociedade soviética que estava arruinada; uma educação que superasse a lógica capitalista, direcionada aos interesses da classe burguesa.

O contexto era também de intensos debates sobre reformas após a guerra e como responder às necessidades educativas da revolução socialista. Influenciado por concepções de Marx, Engels, Lenin e Gorki, Makarenko buscou dar respostas por meio de uma pedagogia baseada na construção da coletividade, que fosse capaz de impulsionar projetos de vida e para a vida (BAÍA; MACHADO, 2019, p. 5).

Conforme Oliveira (2012), na Rússia do início do século XX quase não existia escola pública, visto que em sua maioria os setores da grande burguesia nas áreas urbanas encarregavam-se da função de educar, como foi o caso da escola dos trabalhadores ferroviários, onde Makarenko ensinou por oito anos no início do magistério. No campo, a educação ficava por conta dos latifundiários, cabendo ao poder estatal apenas uma pequena parte das instituições educativas. Desse modo, tanto na zona urbana como na rural, a Igreja era quem administrava a maioria das instituições educacionais e controlava a educação popular, priorizando o ensino do dogma religioso, principalmente na escola primária.

O contexto também propiciou calorosos debates acerca das necessidades educacionais. Então, influenciado por concepções de Marx, Engels, Lenin e Gorki, Makarenko buscava, assim, articular teoria e prática, política e pedagogia. Cabe destacar também a influência de Krupskaia em seu principal preceito, o de coletividade (OLIVEIRA, 2012). A educadora e revolucionária russa valorizou em sua prática e em seus escritos a educação atrelada ao trabalho, tendo como referência suas leituras em Marx e Lenin.

Oliveira (2012) aponta que a principal preocupação da educação comunista para a formação do "homem novo" era a relação entre teoria e prática, e Makarenko atuou nesse sentido, preocupando-se não só com o ensino de matérias e habilidades, mas com a autogestão de suas vidas e da sociedade. Por esse motivo, o estilo literário de Makarenko confunde-se com a sua vida, como pode ser observado em seu Poema Pedagógico, onde na verdade não se trata de um poema, mas de sua biografia e de sua teoria em forma de novela. Assim, tudo em sua vida está interligado e não há como separar a teoria de seu teórico. "Makarenko fez da educação sua vida, da tarefa de educar um caminho para a transformação do homem em pensador revolucionário comprometido com a educação socialista." (MAIA, 2015, p. 71).

Logo, o modelo de educação de Makarenko foi construído ao longo de sua vida, em sua prática pedagógica como professor e diretor da Colônia Gorki e da Comuna Dzerjinski. Embora tenha elaborado 
um modelo visando à formação do novo homem soviético no contexto pós-revolução russa, o mesmo pode ser relacionado aos dias atuais, no sentido de exercer a coletividade em detrimento à individualidade.

Na Colônia Gorki, Makarenko exercia um papel não só pedagógico, mas também político, pois esse trabalho era realizado junto às crianças e aos jovens que precisavam não só dos conhecimentos historicamente construídos pela humanidade, mas também da reabilitação social para libertarem-se da criminalidade e marginalidade, às quais estavam associados.

Percebemos, conforme destacam Cury e Mouta (2014) que, para Makarenko, a educação é um processo que ocorre por meio do esforço e da disciplina, sendo o trabalho coletivo um meio eficaz para atingi-la. Assim, não via o aluno como um aprendiz passivo, ou receptivo de teorias, mas impunha tarefas que exigiam esforço, a fim de desenvolver suas potencialidades e sentimento de pertença ao grupo, cujo objetivo tinha raiz nos ideais revolucionários soviéticos.

$\mathrm{Na}$ comuna, ou colônias dirigidas por ele, os educandos trabalhavam, pois acredita que o trabalho devia ser real e não com fins formativos. A ideia do trabalho coletivo em Makarenko valoriza o educando em sua individualidade, reconhecendo a potencialidade de cada um, fazendo sentir-se responsável pelo sucesso ou fracasso do grupo. Assim, sua pedagogia, a pedagogia russa, não tratava de ensinar conhecimentos ou habilidades, mas de formar personalidades inteiras, formar o educando em sua integralidade. Amboni (2017, p. 312) corrobora com nossa discussão ao compreender que "A escola soviética é, neste caso, uma arma ideológica a serviço da sociedade, cuja premissa básica é a formação do homem na omnilateralidade.”. Esta formação omnilateral seria a base para a transformação do homem e da sociedade.

Para ele, o professor tem o papel de organizar um ambiente que estimule a coletividade, mas é esta que realmente educa os indivíduos (OLIVEIRA, 2012); ou seja, a tarefa do educador é de propiciar um condicionamento social favorável para que os educandos se transformassem em cidadãos de bem, críticos e solidários. Tamanha foi a ênfase dada ao coletivismo que o pedagogo ficou conhecido "o professor do coletivo". De acordo com Pinel e Reses (2017),

A pedagogia socialista de Makarenko, naquele momento, voltada à educação de jovens infratores baseava-se, fortemente, na concepção da escola-reformatório-prisão como um espaço de coletividade tendo, na práxis da afetividade e disciplina, pilares da convivência e educação coletiva. (PINEL; RESES, 2017, p. 319, grifos dos autores).

Apesar de dar autonomia aos jovens da Colônia Gorki e da Comuna Djerzinsk na tomada de decisões, Makarenko era rígido na condução da instituição, praticando até mesmo punições naqueles que não cumpriam as tarefas designadas, em geral era a expulsão do grupo. Não obstante, a principal crítica que recebeu de especialistas em educação deveu-se à rigidez com que conduzia a instituição. De fato, em determinado trecho de "Poema Pedagógico" Makarenko confessa que não sabia educar sem punir, era preciso que alguém lhe ensinasse essa arte (MAKARENKO, 2005, p. 369 apud FEIGEL, 2015). Todavia, foi com essa rigidez que o pedagogo conseguiu reeducar aqueles jovens abandonados e/ou infratores para assumirem o comando de suas vidas e atuarem na sociedade socialista soviética. Sobre a severidade de Makarenko, Cury e Mouta (2014) destacam que "Com mão forte e disciplina unida ao afeto, compreensão 
e valorização, Makarenko logrou índices positivos de melhora no comportamento dos jovens do Centro Gorki, que eram, a princípio, rebeldes e complicados4.” (CURY; MOUTA, 2014, p.19, tradução nossa). Ou seja, o autor pregava que a disciplina não precisava ser ríspida, deveria sim ser dura, séria, mas acompanhada de afeto, carinho.

Outro aspecto a ser destacado na concepção pedagógica de Makarenko, de acordo com Oliveira (2012), é a importância da família para a formação do indivíduo, pois a família deveria servir como um modelo da sociedade coletiva, "Makarenko defende a tese de que a verdadeira família deveria ser uma coletividade eficazmente administrada; para tanto, a criança deve ser, desde seus primeiros anos, um membro dessa coletividade administradora." (OLIVEIRA, 2012, p. 49). Além disso, acreditava que a escola deveria envolver a família no processo educativo, e que a escola devia prepará-la, até mesmo, para o ensino em tempos difíceis, quando a escola, por algum motivo, não puder exercer o seu papel.

Para ele, a família tinha um papel preponderante, e, a fim de incluí-la no processo educativo, sensibilizava os pais que ouviam suas conferências e se comprometiam diante de seus apelos para a construção da nova sociedade disposta a extinguir desigualdades e a ofertar oportunidades e condições de vida digna a todos (BAÍA; MACHADO, 2019, p. 21).

Makarenko ao relacionar trabalho e educação queria formar crianças capazes de dirigir a sua própria vida no presente e a do país no futuro. Por isso, de acordo com Cury e Mouta (2014), ele considerava que a escola deveria ser um espaço em contato com a sociedade e a natureza, permitindo que os educandos atuassem efetivamente na sociedade e participassem das decisões.

A pedagogia socialista de Makarenko o levou a refletir sobre como a atribuição de responsabilidades e o controle social exercido democraticamente mediante a participação viva dos alunos podem ser meios eficientes no processo educativo. Princípios de convivência, cuidados com a limpeza, civilidade, disciplina, zelo com respeito a rotinas e respeito ao trabalho eram firmados por acordos coletivos. Esses eram construídos pelos próprios alunos em meio a debates, exposições e deliberações em assembleias e envolviam desde questões de organização física do espaço a assuntos educacionais, que tivessem possíveis influências na formação de novos hábitos e no convívio entre os diversos sujeitos (BAÍA; MACHADO, 2019, p. 4).

Baía e Machado (2019) classificam Makarenko como um pedagogo do extremo e da alegria de educar. Do extremo, seguindo a designação de Casanova e Pesce (2011) que designam pedagogo do extremo, porque, mesmo em meio a diversos desafios sociais ocasionados pela pobreza e violência, consegue construir saídas e realidades que dão esperança. "Esse também foi o quadro enfrentado por Makarenko, que buscou se armar observando as necessidades sociais e do mundo da classe trabalhadora e os fundamentos do marxismo referentes à construção da emancipação social." (BAÍA; MACHADO, 2019, p. 3).

\section{Contribuições da Pedagogia de Makarenko à escola brasileira}

A concepção pedagógica de Anton Makarenko atualmente pode ser encontrada nos seus escritos, nos quais descreve a sua experiência pedagógica por onde passou. Muitos dos desafios que encontrou como educador são os mesmos que os professores enfrentam atualmente no seu dia a dia, por 
isso as soluções que encontrou para obter bons resultados com seus alunos podem auxiliar os professores da escola contemporânea a superarem seus desafios.

Makarenko, assim como muitos professores e professoras, teve que lidar com situações adversas e superar os obstáculos que dificultavam o processo de ensino-aprendizagem e obteve êxito ao utilizar um método que tinha como base o trabalho coletivo. Além do trabalho, sua pedagogia também estava focada na vida em grupo, na autogestão e na disciplina (CURY; MOUTA, 2014, p. 18). O pedagogo foi além da função de ensinar conhecimentos e habilidades para o mercado de trabalho, além disso, encontrou meios de fazer com que aqueles jovens, antes considerados perdidos ou contraventores, assumissem o controle de suas vidas, preparando-os para a vida em sociedade, não apenas com teorias abstratas, mas por meio do exercício diário de atividades, que exigiam deles responsabilidade, e do trabalho em grupo.

Diante da concepção educacional de Makarenko, cabe-nos refletir sobre que tipo de educação nós estamos oferecendo aos nossos alunos. Será que estamos propiciando meios para que estes se sintam parte de um todo ou estamos formando indivíduos cada vez mais competitivos e individualistas? Nossos alunos preocupam-se apenas com o sucesso pessoal ou entendem o sucesso pessoal como consequência de um trabalho coletivo? Que tipo de indivíduo a escola brasileira está formando? São questionamentos para os quais não apontamos respostas, porque cabe a cada educador refletir sobre.

Ruiz (2008) pondera que o trabalho coletivo não parece uma realidade nas escolas brasileiras, pois é muito difícil desenvolver um trabalho coletivo numa sociedade com classes sociais tão antagônicas como a sociedade brasileira, destarte o que impera na escola capitalista são os valores mercadológicos e neoliberais, nos quais imperam a competitividade, a meritocracia e o individualismo.

Sabemos que existem muitas questões educativas que só dependem do Estado, entretanto compreendemos que outras podem ser mediadas por nós, professores atuantes em sala de aula. Neste sentido, Makarenko nos inspira a, diante da realidade que nos é apresentada, nos debruçarmos no processo ensino-aprendizagem e encontrarmos as estratégias mais adequadas a fim de promovermos uma formação mais holística dos nossos estudantes. Makarenko não encontrou nos modelos vigentes a solução para os problemas que encontrava no dia a dia, por isso aos poucos criou o seu método, o que melhor atendia às necessidades do contexto ao qual estava inserido.

Makarenko preocupou-se com a formação que ocorria para além dos muros da escola, pensando na sociedade e na família que, para ele, tinha papel fundamental na formação do indivíduo, e acreditava que a escola deveria ocupar-se até mesmo com a educação dos pais, formando-os para exercerem a função da escola em tempos difíceis. Nesse sentido, vale a reflexão: numa situação de pandemia, como a do Corona vírus que estamos vivendo nos dias atuais, impedindo que crianças e jovens frequentem a escola, as nossas famílias brasileiras estão preparadas para assumir a função da escola? De certo não estão! Pelo menos as famílias menos abastadas, não estão! Tal situação exige das famílias, além de disponibilidade e de uma série de habilidades para auxiliar o processo de aprendizagem de seus filhos, recursos básicos e infraestrutura que, lhes são negados pelo próprio Estado. É certo que a escola brasileira, também não está preparada para essa nova realidade, porém, valendo-se do precário ensino remoto, continuou suas atividades em todos os níveis da educação. 
Embora se pondere como negativo na teoria de Makarenko, que tem a ideia de homem perfeito postulada pelo regime soviético, a intolerância ao erro e aos castigos empregados, consideram-se relevantes alguns aspectos que podem ser mais apreciados na educação brasileira nos tempos atuais: a importância da família na educação dos filhos, o espaço para a voz aos educandos nas tomadas de decisões, o desenvolvimento do sentimento de pertencimento a um grupo, fazendo-os sentirem-se responsáveis pelo sucesso ou pelo fracasso e, principalmente, a superação do individualismo por meio da autogestão coletiva. Finalmente, considera-se de suma importância refletir sobre a concepção pedagógica do referido pedagogo russo em relação ao coletivo e à disciplina em virtude de, um século após suas experiências pedagógicas, ainda encontrarem-se pertinentes e atuais.

\section{Considerações finais}

O presente artigo discutiu a atualidade da concepção pedagógica de Anton Makarenko, pedagogo da Ucrânia, país que fez parte da União Soviética por quase todo o século XX, e atuante nessa sociedade como professor e diretor de instituições que tinham como público crianças e jovens abandonados e/ou infratores.

Assim como a concepção pedagógica de Makarenko está entrelaçada com a sua história de vida, neste artigo fez-se uma breve análise biográfica, entrelaçada à sua teoria pedagógica construída ao longo de sua prática pedagógica nas três sedes onde funcionou a Colônia Gorki e na Comuna Dzerjinski.

Verificou-se que a autogestão coletiva era a base da pedagogia do pedagogo ucraniano e que considerava o professor o responsável por organizar a coletividade, que por sua vez, era o que de fato formava para a vida em sociedade, segundo Makarenko. Sua pedagogia não tratava só de ensinar conhecimentos ou habilidades, mas de formar o educando em sua integralidade. Por isso, nas colônias e na comuna o trabalho devia ser real e não com fins formativos. Nessas instituições os educandos não só estudavam, mas também trabalhavam e tinham voz nas tomadas de decisões. Porém, Makarenko tinha um modelo de cidadão comunista que não aceitava falhas, eliminando do grupo aqueles que não cumpriam com suas responsabilidades, de modo que seu trabalho foi duramente criticado por especialistas da educação, sendo a rotina na Colônia Gorki comparada a uma rotina militar. Antes de sua morte, teve sua pedagogia reconhecida, recebendo a condecoração da Ordem da Bandeira Vermelha do Trabalho, em virtude de sua contribuição à educação soviética.

Atualmente alguns aspectos de sua teoria são questionáveis, mas o que não se pode negar é a revolução social realizada ao propor uma educação que dá voz ao educando e que prioriza a coletividade. Esse aspecto aliado a outros, como a importância da família na formação para a cidadania e a superação do individualismo, podem ser apreciados pela educação brasileira, principalmente nesta época de COVID19, em que a escola passou a ser o próprio lar do estudante. As famílias então têm a oportunidade de vivenciarem a desafiadora missão de ensinar, principalmente em um momento político em que o Brasil precisa de cidadãos críticos e reflexivos para transformar a realidade social fascista e anticientificista para a qual se encaminha. 


\section{Referências bibliográficas}

AMBONI, V. O trabalho como referência educacional na formação do homem soviético. Germinal: Marxismo e Educação em Debate, Salvador, v. 9, n. 3, p. 307-316, dez. 2017. Disponível em: $<$ https://portalseer.ufba.br/index.php/revistagerminal/article/view/24508>. Acesso em: 31 mai. 2020.

ARANHA, M. L. A. História da educação e da pedagogia: geral e Brasil. São Paulo: Moderna, 2006.

BAÍA, S. F.; MACHADO, L. R. S. Makarenko, pedagogo do estremo e da alegria de educar. HISTEDBR On-line, Campinas, SP: V.19, P. 1-11, 2019. Disponível em:

$<$ https://periodicos.sbu.unicamp.br/ojs/index.php/histedbr/article/view/8654460/20853>. Acesso em: 03 jun. 2020.

BRETAS. S. A.; NOVAES. K. G. O conceito de coletividade de Anton Makarenko, em seu Poema pedagógico. Rev. Bras. Estud. Pedagog. (online), Brasília, v. 97, n. 246, p. 402-423, maio/ago. 2016. Disponível em: <https://www.scielo.br/pdf/rbeped/v97n246/2176-6681-rbeped-97-246-00402.pdf>. Acesso em: 08 jun. 2020.

CURY, L.; MOUTA, A. C. L. Explorando las interfaces comunicación-educación: el método Makárenko y los talleres de comunicación de los centros juveniles de la ciudad de Santos (Brasil). Contratexto, Lima, v. no 2014, n. 22, P. 15-33, 2014. Disponível em: <

http://www3.eca.usp.br/sites/default/files/form/biblioteca/acervo/producao-

academica/002657689.pdf > DOI: 10.26439/contratexto2014.n022.86. Acesso em: 16 jun. 2020.

FEIGEL, G. L. R. O Poema Pedagógico de Anton Makarenko. Revista de Ciências Humanas, v. 49, n. 1, p. 110-115, jan-jun 2015. Disponível em:

<https://periodicos.ufsc.br/index.php/revistacfh/article/view/2178-4582.2015v49n1p110/29609>.

Acesso em: 02 jun. 2020.

FERREIRA; J. V. R.; MARAFON, F.; SANTOS, A. R. J. Anton Makarenko: caminhos alternativos na realidade educacional atual. Disponível em:

<http://www.histedbr.fe.unicamp.br/acer_histedbr/seminario/seminario8/_files/UjGd5Vca.pdf>.

Acesso em: 02 jun. 2020.

FILONOV, G. N. Anton Makarenko. Tradução de Ester Buffa. Organização de Carlos Bauer e Ester Buffa. Recife: Fundação Joaquim Nabuco, Editora Massangana, 2010. Disponível em:

<http://livros01.livrosgratis.com.br/me4659.pdf>. Acesso em: 03 jun. 2020.

MAIA, L. A. A pedagogia socialista de Makarenko: notas pedagógicas. Dialectus. Ano 2, n. 7, Setembro Dezembro 2015, p. 68-81, 2015. Disponível em:

<http://periodicos.ufc.br/dialectus/article/view/5183/3815>. Acesso em: 03 jun. 2020.

OLIVEIRA, C. M. A formação do homem novo na pedagogia de Anton S. Makarenko: um estudo introdutório na perspectiva da ontologia marxiana-lukacsiana. 2012. 115f. Dissertação (Mestrado em Educação)- Universidade Federal do Ceará. 2012. Disponível em: < http://www.uece.br/ppge/wpcontent/uploads/sites/29/2019/06/Disserta\%C3\%A7\%C3\%A3o_CIRO-MESQUITA-DEOLIVEIRA.pdf $>$. Acesso em: 02 jun. 2020.

PINEL, W. R.; RESES, E. da S. A pedagogia de Makarenko: aproximações de um modelo socioeducativo na revolução russa. Germinal: Marxismo e Educação em Debate, Salvador, v. 9, n. 3, p. 317-324, dez. 2017. Disponível em: <https://portalseer.ufba.br/index.php/revistagerminal/article/view/24656>. Acesso em: 25 mai. 2020.

RUIZ, M. J. F. Trabalho coletivo na escola pública: contribuições pedagógicas de Anton Semionovitch Makarenko. ORG \& DEMO, Marília, v.9, n.1/2, p. 223-240, jan./dez.2008. Disponível em: file:///D:/Documents/62-Texto\%20do\%20artigo-225-1-10-20100108\%20(1).pdf. Acesso em: 02 jun. 2020.

\section{Notas}


${ }_{1}^{1}$ Mestranda do Programa de Pós-Graduação em Ensino de Ciências e Matemática do Instituto Federal de Educação, Ciência e Tecnologia (IFCE); http://dgp.cnpq.br/dgp/espelhorh/6267402154400258\#gruposPesquisa http://lattes.cnpq.br/9462717576751357; https://orcid.org/0000-0001-9566-4966; ssfrazao@hotmail.com.

2 Doutora em Educação pela Universidade Federal do Ceará (UFC); http://dgp.cnpq.br/dgp/espelhorh/6267402154400258\#gruposPesquisa; Programa de Pós-Graduação em Ensino de Ciências e Matemática do Instituto Federal de Educação, Ciências e Tecnologia (IFCE); http://lattes.cnpq.br/6267402154400258; https://orcid.org/0000-0001-5577-9523; ccleideifcemaraca@gmail.com.

3 No original: [...] que sea trabajador y culto, que sepa comandar y subordinarse en una sociedad que tiene como fi nalidad abolir las diferencias de clases.

${ }^{4}$ No original: Con mano dura y disciplina unida al afecto, comprensión y valorización, Makárenko logró índices positivos de mejora en el comportamiento de los jóvenes del Centro Gorki, que eran, al principio, rebeldes y complicados.

Recebido em: 24.06 .2020

Aprovado em: 12.08 .2020 